\title{
Correspondence
}

\author{
Suicide: Don't wait for the publicity \\ DEAR SirS \\ Several times recently people who have just had an \\ in-patient suicide have asked me what to do, ${ }^{*}$ and whether the \\ College recommends any procedure. It might be a good idea if \\ the College, possibly through the Public Policy Committee, \\ did publish a recommended scheme of audit for suicide, or a \\ medical inquest. In the meanwhile may I offer some \\ suggestions?
}

A medical inquest is not to decide if it was suicide, or if anyone is to blame. Starting from the facts that a patient of the hospital has killed himself/herself by a specific method at a specific place, time and date, it has a psychological function and a teaching function. By bringing people together to talk about their roles in the common work of the hospital it is a morale-builder. By drawing together all those who cared for the dead person it allows mourning, and the staff will feel better. By examining together the sequence of events which ended in the death, people can learn whether they collectively or individually needed more knowledge or a different procedure.

Not all in-patient suicides are avoidable, but some are. I have known of visitors or fellow-patients who brought in razors or drugs and gave them to a person known to the staff to be at risk. I have known of a ward where the number of disturbed patients was quite out of balance with the few staff on duty. I have known of failures of communication between staff members or with the world outside the hospital, some due to unsatisfactory procedures, others to secretarial misapprehensions or telephonic inadequacies. The medical inquest is to see whether the hospital and community services are working as efficiently as they might and, if not, to try to improve them.

This inquest takes place at two levels, or in two parts. In the first, all the team involved in the care of the dead person meet together to establish the details of the events which ended in the death. In the second part the professional managers of the hospital and external services-consultants, nursing officers, administration, perhaps social work leader-consider the details, and compare them with those of other recent suicides to see if any changes in practice are needed.

The first part requires the attendance of consultant and nursing officer, the ward charge nurses of all shifts, the junior doctor(s) of the team, possibly the patient's GP, social workers and psychologist (where involved in care), nurses who knew the patient, any secretaries who do the team's clerical work, and possibly the hospital engineer or other specialist. Basically they look at three things:

1. The assessments of suicidal risk at admission to hospital and just prior to suicide made by medical and nursing members: was full knowledge of the patient's history obtained, and was it known to all staff? (With hindsight,

*Perhaps arising from papers in the Bulletin. January 1983, 7. 2-4; and in the Journal. November 1984, 145, 460-3. would it have been better if someone had obtained additional history, or if there were better communications between staff at some points-how?; or if some staff were more informed of up-to-date knowledge about suicide- - a training matter?)

2. How did the patient get to the (unobserved) place where the suicidal act was made? This may mean looking at how a patient went missing or was granted leave, or the degree and quality of nursing observation on the ward at the time. Sometimes there are delays in carrying out procedures, or they are found to be unworkable in part. Again, hindsight is valuable in reviewing what happened and how it could have been avoided in ideal circumstances.

3. How was the particular method of suicide available to the patient at that time-e.g. jumping down stair wells or out of open upstairs windows, hanging from lavatory chains, acquiring knives or stocks of tablets? (Patients often have preferred methods of sicide. A patient of mine in South London went to Victoria and caught a train to Brighton, in order to throw herself into the sea and drown there. Denying her a railway ticket (by holding her money) during the time she felt particularly suicidal might have prevented this.)

The second part of the medical inquest is concerned with the death as it affects the whole hospital, and possibly community services. Admissions policies, disposition of nursing staff, training of staff, hospital procedures for different emergencies, harmony between psychiatric and general wards, co-operation with GPs, social services and voluntary agencies may all need to be considered.

These suggestions are full, but of course need modification to suit different types of psychiatric unit, and possibly different types of suicide. They are made because a breadth of inquiry is likely to be useful if medical audit is to improve service to the patient and to the community and help staff to overcome their feelings of guilt and failure.

J. L. Crammer

Institute of Psychiatry

London SES

\section{Mental handicap and the Mental Health Act}

DeAr Sirs

I also share the concern of Dr T. Hari Singh about the provisions of the Mental Health Act as they relate to mentally handicapped people (Bulletin, January 1985, 9, 14).

It is right that the intention of the legislation was to protect the 'rights' of mentally handicapped people but, leaving aside the question of what 'rights' actually means, I think the Act was trying to do something more complicated than that. The substitution of the term 'mental impairment' for 'subnormality' was an attempt to remove most mentally handicapped people from the long-term compulsory hospital admission sections of the Mental Health Act. Underlying this move was the feeling that the legislation concerning the care of mentally 